\title{
Assessment of bovine tuberculosis and its risk factors in cattle and humans, at and around Dilla town, southern Ethiopia
}

\author{
Gebremedhin Romha ${ }^{1, *}$, Gebremedhin Gebre egziabher², Gobena Ameni ${ }^{3}$ \\ ${ }^{1}$ Dilla University, College of Agriculture and Natural Resource, Department of Animal and Range Science, P.O. Box 419, Dilla, Ethiopia \\ ${ }^{2}$ Samera University, College of Veterinary Medicine, P.O. Box 132, Samera, Ethiopia \\ ${ }^{3}$ Aklilu Lemma Institute of Pathobiology, Addis Ababa University, P.O. Box 1176, Addis Ababa, Ethiopia
}

\section{Email address:}

gebremedhinromha@yahoo.com (G. Romha), greatmedhin2010@gmail.com (G. G. egziabher), gobenachimidi@yahoo.co.uk (G. Ameni)

\section{To cite this article:}

Gebremedhin Romha, Gebremedhin Gebre egziabher, Gobena Ameni. Assessment of Bovine Tuberculosis and Its Risk Factors in Cattle and Humans, at and around Dilla Town, Southern Ethiopia. Animal and Veterinary Sciences. Vol. 2, No. 4, 2014, pp. 94-100.

doi: $10.11648 /$ j.avs.20140204.12

\begin{abstract}
A cross-sectional study was carried out from February, 2012 to June, 2013 using comparative intradermal tuberculin (CIDT) test on 440 individual live cattle kept in 118 housholds/farms to determine the prevalence of, and to identify the risk factors associated with, bovine tuberculosis (BTB) infection in cattle and to assess the public awareness on its zoonotic importance through structured questionnaires at and around Dilla town, southern Ethiopia. The herd and individual cattle prevalence of bovine tuberculin positivity were $15.3 \%$ (95\%, Confidence interval (CI): 8.7 to 21.8 ) and $4.3 \%$ (95\%, CI: 2.4 to 6.2), respectively at cut-off greater than $4 \mathrm{~mm}$. The herd prevalence of BTB varied significantly among herd size $(\mathrm{P}=0.019)$ and management conditions $(\mathrm{P}=0.031)$. Herds which had 5-9 and more than 9 cattle were six (Odds ratio $(\mathrm{OR})=6.4)$ and twelve $(\mathrm{OR}=12.0)$ times more reactive to bovine tuberculin testing than herds that had less than or equals to four cattle in their farms. Among the animal related risk factors only breed $(\mathrm{P}=0.020)$ had a significant association with the prevalence of bovine tuberculin positivity with the highest odds ratio in Holstein breeds $(\mathrm{OR}=6.1)$ as compared to Zebu and cross (Holstein X Zebu) breeds. Less than one third (29.7\%; 35 of 118) of the respondents recognized BTB, and only $22.9 \%(27 / 118)$ of the respondents had understanding of its zoonotic implication. Awareness rising of cattle owners about BTB and its transmission, and the zoonotic implication of BTB is of extreme importance for effective implementation of TB control measures.
\end{abstract}

Keywords: Bovine Tuberculosis, CIDT Test, DillaTown, Awareness, Risk Factors, Ethiopia

\section{Introduction}

It is well known that humans and animals have had close interactions. The interaction is becoming largely increased in the $21^{\text {st }}$ century due to the shift from extensive rural production system into the combined urban and peri-urban intensified livestock husbandry to satisfy the rise in demand for animal products. This largely contributes to the ongoing transmission of shared infectious zoonotic diseases from cattle to humans [1]. Bovine tuberculosis among the principal zoonotic diseases [2] caused by Mycobacterium bovis, member of the Mycobacterium tuberculosis complex (MTC), which affects many vertebrate animals and humans, and characterized by progressive development of granulomas in tissues and organs [3,4].
Tuberculosis (TB) caused by bovine origin has emerged as a significant disease with the tendency for inter-species spread. Bovinetuberculosis has been significantly widely distributed throughout the world and has been a cause for great economic loss in animal production and the most frequent cause of zoonotic TB in man [5]. In developed countries, mandatory pasteurization of milk combined with tuberculin testing and culling (slaughter) of infected cattle resulted in dramatic decline in the incidence of human TB due to Mycobacterium bovis (M. bovis) [6]. In Africa; however, BTB represents a potential health hazard to both animals and humans, as nearly $85 \%$ of cattle and $82 \%$ of the human population live in areas where the disease is prevalent or only partially controlled [7]. In developing countries where BTB is still common and pasteurization of 
milk is not practiced, an estimated 10 to $15 \%$ of human TB cases are caused by M. bovis [8].

In Africa though BTB represents a potential health hazard to both animal and human populations as in most developing countries, $M$. bovis infection remains largely uninvestigated. Its epidemiology and public health significance remains largely unknown due to several factors including the high cost of testing programme, social unrest due to political instability, ethnic wars resulting in displacement of large numbers of people and animals, and a lack of veterinary expertise and communication networks [9-14].

In Ethiopia, BTB is considered to be a prevalent disease in cattle populations. Tuberculin skin test survey indicates that the prevalence ranges from $0.8 \%$ in extensive rural farming systems that keep Zebu cattle to $50 \%$ in intensive husbandry systems (15-19).Few studies have also indicated the disease is zoonotic; transmitted from animal to humans and vice versa $[9,16,20]$.

Many studies have shown that there are many risk factors conducive to the spreading and persistence of BTB in developing countries such as demography, eating habits, living and socio-economic status of families, illiteracy, culture and customs, the existence of HIV/AIDS, and close proximity with animals [11,16,21-23]. Ethiopian milk consumers generally prefer raw milk (as compared to treated milk) because of its taste, availability and lower price. The zoonotic risk of BTB is often associated with consumption (ingestion) of dairy products based on unpasteurized milk infected with M. bovis. Also, aerosol transmission from cattle-to-human should also be considered as a potential risk factor [16, 19, 24, 25].

In Ethiopia, the epidemiology of BTB is not well established in livestock, and most studies have been focused mainly around the central part of the country. In order to embark the national BTB control program in the future, the epidemiology of the disease has to be assessed widely in all regions of the country where such study has not yet been conducted. The objectives of the present study are therefore to determine the prevalence of, and to identify the risk factors associated with, BTB infection in cattle and to assess the public awareness on its zoonotic importance at and around Dilla town, southern Ethiopia.

\section{Materials and Methods}

\subsection{Description of the Study Site and Population}

The study was conducted at Dilla town and its surroundings, southern Ethiopia. Dilla town is the capital of Gedeo zone, located $359 \mathrm{kms}$ from Addis Ababa, the capital of Ethiopia.The geographical location of the research site is $5^{0}$ to $7^{0}$ North latitudes and $38^{0}$ to $40^{\circ}$ East longitudes in the escarpment of the Rift Valley at an elevation ranges from 1200 to 3175 meters a.s.l. The climate of Dilla town is characterized as warm humid temperate. Mean annual temperature ranges between $17^{\circ} \mathrm{C}$ and $22.4^{\circ} \mathrm{C}$ and mean annual rainfall between 1200 and $1800 \mathrm{~mm}$. Dilla town is thus endowed with two rainy seasons, from March to May and from July to December [26]. The study populations were cattle originated from Dilla town and its surroundings and people who reared these animals.

\subsection{Study Design and Sampling Method}

A cross-sectional study was conducted from February, 2012 to June, 2013 using comparative intradermal tuberculin (CIDT) test on 440 live cattle to determine the prevalence of $\mathrm{BTB}$ and to identify the risk factors associated with BTB infection in cattle. Moreover, a questionnaire survey was carried out through structured questionnaires format to assess the knowledge and awareness of cattle owners on BTB and its zoonotic importance as well as the routes of transmission of the disease.The sample size for tuberculin testing was calculated using the cluster sampling formula described by Bennett et al. [27]. We assumed an intra-class correlation coefficient (rho) of 0.2 , an expected prevalence of $11.6 \%$ and standard error of $2.0 \%$. The total sample size calculated for 118 households/farms was $n=440$ cattle.

The standard error (s.e.x) which measures the precision of our estimate is given by (i):

$$
\text { s.e.x }=\sqrt{\frac{p q D}{n}}=\sqrt{\frac{p q D}{c b}}
$$

Rho ( $\rho$ ) describes the rate of homogeneity, thus the variability is given by (ii):

$$
\begin{gathered}
\rho=\frac{\text { (withinHerd Variation })}{\text { TotalVaria tion }} \\
\mathrm{D}=1+(\mathrm{b}-1) \rho
\end{gathered}
$$

Where $\rho=$ rho, s.e $=$ standard error, $\mathrm{D}=$ design effect, $\mathrm{b}$ $=$ samples per cluster, $\mathrm{c}=$ number of clusters, $\mathrm{q}=1-\mathrm{p}$ and $\mathrm{p}$ $=$ expected prevalence [28].

A list of households interested to participate in the study was established through the support of the agricultural and rural development office of the zone and used as a sampling frame. Thus, households/farms were considered as primary units; while individual animal were used as secondary units. The primary stage was sampling of households those who owned smallholder dairy farms. In secondary stage, animals within households were selected. Both the primary and secondary units were randomly selected (using random number technique). Thirty percent of each of the selected herds was included in the study. Accordingly, a total of 440 cattle belong to 118 households were selected in this study.

\subsection{Study Methodology}

Comparative intradermal tuberculin test was conducted on 440 live cattle using both avian and bovine purified protein derivates (PPD) (Lelystad Biological BV. Lelystad, 
Netherlands) kindly donated by the Animal Health and Veterinary Laboratories Agency (UK). Test procedures and interpretation of the results were done according to the procedures documented in OIE [4]. Management and other important data like animal age, breed, body condition score (BCS), sex, lactation status, pregnancy status, parity class and skin test measurements were recorded. Young cattle $\leq 6$ months of age, and cows in late pregnancy and those recently calved were excluded in the study for fear of immune dysfunction that usually occurs in dairy cows starting around 3 weeks pre-calving to 3 weeks postcalving [29].

All animals in this study were thoroughly observed for their body condition. Body condition scoring was done according to the established guide lines [30]. The management of the farms was categorized as described by Ameni et al. [31] on the basis of housing condition (neatness, waste disposal, nature of the floor, presence of confinement), feeding (concentrate plus hay), possession of an exercise yard, and contact with other herds and provision with clean water. Structured questionnaires were prepared and administered to cattle owners or herders to collect data on the role of various risk factors for the occurrence and spread of BTB among cattle, and between cattle and human. A total of 118 cattle owners or farm workers were interviewed on the same day when their cattle were tested for BTB.

\subsection{Data Analysis}

Cattle skin test data at individual and herd level were recorded in database based on Microsoft ${ }^{\circledR}$ Excel for
Windows 2007. Statistical analysis was carried out using STATA 11 Statistical Software (STATA Corporation, College Station, TX). Individual animal prevalence was defined as the number of positive reactors per 100 animals tested. The farm level prevalence was calculated as the number of herds with at least one-reactor animal per 100 herds tested. Chi-square $(\chi 2)$ and multivariate logistic regression analyses were used to examine the effect of risk factors on animal prevalence $(\mathrm{P})$. A P-value $<0.05$ was considered to be statistically significant.

\subsection{Ethical Clearance and Consideration}

Our research work was evaluated and approved by the Institutional Review Board (IRB) of the Aklilu Lemma Institute of Pathobiology, Addis Ababa University. The Reference Number of the approval letter is IRB/01/201213. Consent was obtained after the purpose of the study was explained to the owners of animals.

\section{Results}

\subsection{Herd Level Prevalence and Risk Factors}

The herd level prevalence of BTB was 18/118 (15.3\%) (95\%, CI: 8.7 to 21.8).The herd prevalence of BTB varied significantly among herd size $(\mathrm{P}=0.019)$ and management conditions $(\mathrm{P}=0.031)$ (Table 1$)$. Those herds which had 5-9 and more than 9 cattle were six $(\mathrm{OR}=6.4)$ and twelve $(\mathrm{OR}=12.0)$ times more reactive to bovine tuberculin testing than herds that had less than or equals to four cattle in their farm (Table 1).

Table 1. Evaluation of the association of risk factors to herd tuberculin test results at and around Dilla town, southern Ethiopia.

\begin{tabular}{|c|c|c|c|c|c|}
\hline Variable & Number tested & Number Positive (\%) & $\chi 2$-value & P-value & OR(95\%CI) \\
\hline Herd size & & & 7.9 & $0.019 *$ & \\
\hline$<4$ & 36 & $1(2.8)$ & & & 1 \\
\hline $5-9$ & 39 & $6(15.4)$ & & & $6.4(1.9-55.7)$ \\
\hline$>9$ & 43 & $11(25.6)$ & & & $12.0(1.5-38.5)$ \\
\hline House hold history of HTB & & & 0.3 & 0.581 & \\
\hline Absent & 114 & $17(15.0)$ & & & 1 \\
\hline Present & 4 & $1(25.0)$ & & & $4.0(0.2-89.7)$ \\
\hline Management & & & 4.7 & $0.031 *$ & \\
\hline Poor & 34 & $9(26.5)$ & & & 1 \\
\hline Good & 84 & $9(13.1)$ & & & $0.2(0.1-0.9)$ \\
\hline Presence of other livestock & & & 0.04 & 0.841 & \\
\hline Absent & 63 & $8(14.6)$ & & & 1 \\
\hline Present & 55 & $10(15.9)$ & & & $2.8(0.2-2.2)$ \\
\hline Presence of wild life & & & 1.7 & 0.197 & \\
\hline Absent & 91 & 16(17.6) & & & \\
\hline Present & 27 & $2(9.5)$ & & & $1.3(0.1-6.2)$ \\
\hline
\end{tabular}

* Statistically significant $(\mathrm{P}<0.05), \mathrm{HTB}=$ Human TB

\subsection{Animal Level Prevalence and Risk Factors}

The prevalence of bovine tuberculin positivity at individual animal level was 19/440 (4.3\%)(95\%, CI: 2.4 to
6.2) at cut-off greater than $4 \mathrm{~mm}$. Among the animal related risk factors only breed $(\mathrm{P}=0.020)$ had a significant association with the prevalence of bovinetuberculin positivity. Holstein breeds were $(\mathrm{OR}=6.1)$ six and three 
times more reactive to bovine tuberculin testing when compared to Zebu and cross (Holstein X Zebu) breeds,

respectively(Table 2).

Table 2. Evaluation of the association of selected animal risk factors with prevalence of bovine tuberculin positivity at and around Dilla town, southern Ethiopia.

\begin{tabular}{|c|c|c|c|c|c|}
\hline Variable & Number tested & Number positive (\%) & $\chi 2$ Value & P-value & OR(95\%CI) \\
\hline Sex & & & 0.12 & 0.726 & \\
\hline Female & 382 & $17(4.5)$ & & & 1 \\
\hline Male & 58 & $2(3.5)$ & & & $0.8(0.2-3.2)$ \\
\hline Age (Yrs) & & & 1.15 & 0.765 & \\
\hline$<2$ & 99 & $3(3.0)$ & & & 1 \\
\hline 2- 4 & 142 & $6(4.3)$ & & & $1.4(0.3-7.8)$ \\
\hline 4- 7 & 162 & $9(5.6)$ & & & $1.9(0.4-9.7)$ \\
\hline$>7$ & 37 & $1(2.7)$ & & & $0.9(0.1-11.1)$ \\
\hline Breed & & & 7.80 & $0.020^{*}$ & \\
\hline Local & 117 & $2(1.7)$ & & & 1 \\
\hline Cross & 240 & $9(3.8)$ & & & $2.2(0.6-8.9)$ \\
\hline Exotic & 83 & $8(9.6)$ & & & $6.1(1.3-29.5)$ \\
\hline Body condition & & & 0.17 & 0.920 & \\
\hline Poor & 60 & $2(3.3)$ & & & 1 \\
\hline Medium & 69 & $3(4.3)$ & & & $1.3(0.2-8.5)$ \\
\hline Good & 311 & $14(4.5)$ & & & $1.4(0.3-5.7)$ \\
\hline Lactation & & & 1.04 & 0.307 & \\
\hline Non lactating & 203 & $7(3.4)$ & & & 1 \\
\hline Lactating & 179 & $10(5.6)$ & & & $1.7(0.6-4.5)$ \\
\hline Pregnancy & & & 3.40 & 0.065 & \\
\hline Non pregnant & 261 & $15(5.8)$ & & & 1 \\
\hline Pregnant & 121 & $2(1.7)$ & & & $0.3(0.1-1.2)$ \\
\hline Parity class & & & 3.51 & 0.173 & \\
\hline Heifer & 169 & $4(2.4)$ & & & 1 \\
\hline Parity 1-3 & 186 & $12(6.5)$ & & & $2.8(0.9-9.1)$ \\
\hline Parity $>4$ & 27 & $1(3.7)$ & & & $1.6(0.2-14.7)$ \\
\hline
\end{tabular}

* Statistically significant $(\mathrm{P}<0.05)$

\subsection{Assessment of Cattle Owners Awarness on Bovine Tuberculosis}

The knowledge on the role of various risk factors responsible for the occurrence and spread of BTB between cattle and people were assessed by a questionnaire on a total of 118 farm owners (households) and the result is depicted in Table 3. As can be seen from Table3, about $29.7 \%$ (35 of 118 ) of the respondents knew that cattle can have TB, and $22.9 \%$ (27 of 118) responded that bovine TB can transmit from animal to human and vice versa. The life style and consumption habit of the 118 respondents is shown in Table 4. Several demographic characteristics and other factors were considered to investigate their possible association with BTB recognition of the respondents. The awareness of the respondents regarding cattle infection with BTB and the transmission of BTB from cattle to man improved as the educational background of the respondents increased (data not shown).
Table 3. Knowledge of cattle owners about bovine tuberculosis and its transmission to humans in the study area.

\begin{tabular}{lcc}
\hline $\begin{array}{l}\text { Knowledge examined in } \\
\text { Questionnaire }\end{array}$ & $\begin{array}{c}\text { Number } \\
\text { interviewed }\end{array}$ & $\begin{array}{c}\text { Correct } \\
\text { response (\%) }\end{array}$ \\
\hline TB can affect animals & 118 & $35(29.7)$ \\
TB is zoonotic & 118 & $27(22.9)$ \\
$\begin{array}{l}\text { Drinking raw milk is source of } \\
\text { infection for TB }\end{array}$ & 118 & $31(26.3)$ \\
$\begin{array}{l}\text { Eating raw meat is source of infection } \\
\text { for TB }\end{array}$ & 118 & $29(24.6)$ \\
$\begin{array}{l}\text { TB cough spray is source of infection } \\
\text { for TB }\end{array}$ & 118 & $27(22.9)$ \\
$\begin{array}{l}\text { Sharing the same house is source of } \\
\text { infection for TB }\end{array}$ & 118 & $26(22.0)$ \\
\hline
\end{tabular}


Table 4. Life style, and milk and meat consumption habit of cattle owners in the study area.

\begin{tabular}{lcc}
\hline Habit of respondents & $\begin{array}{c}\text { Number } \\
\text { interviewed }\end{array}$ & Percent (\%) \\
\hline Milk drinking & 118 & $19(16.1)$ \\
Boiled milk & 118 & $95(80.5)$ \\
Both raw and boiled milk & 118 & $4(3.4)$ \\
Do not consume milk at all & & \\
Meat eating habit & 118 & $25(21.2)$ \\
Cooked meat & 118 & $93(78.8)$ \\
$\begin{array}{l}\text { Both cooked and raw meat } \\
\text { House sharing (live close to their } \\
\text { animals) }\end{array}$ & & \\
Not sharing & 118 & $41(34.8)$ \\
Sharing & 118 & $77(65.3)$ \\
\hline
\end{tabular}

\section{Discussion}

Discordant with the previous reports [19, 32, 33], this study discovered low prevalence of BTB in the study area. This could be due to the fact that the present study was conducted in smallholder farms with smaller herds, in which some animals were kept in the open air in contrast to previous studies, which were conducted on relatively large herd-sized farms. The transmission of BTB from cattle to cattle is largely influenced by herd size; the larger the herd size the greater the chance of transmission [34]. However, congruent with the result of the present study, low prevalences of BTB have been reported in smallholder dairy farms [29] and in cattle of rural livestock production systems in Ethiopia [18]. When larger proportion of the study animals was grazing in the field, the level of confinement is reduced to a certain degree, which in turn minimizes the rate of infection in the herd [35].

In this study herd tuberculin result showed a statistically significant association with herd management conditions suggesting that poor managerial inputs increase the risk of BTB. Previous studies similarly have reported higher infection rates in farms under poor management conditions $[29,30,36]$. It can therefore be generalised that the status of BTB could be improved by adopting sanitary measures that improve hygiene conditions on farms. Moreover, in the present study, pure Holstein breeds $(\mathrm{OR}=6.1)$ were six and three times more reactive to bovine tuberculin positivity as compared to Zebu and cross (Holstein X Zebu) breeds, respectively which is similar with earlier reports $[10,20,37]$.The probable reason could be the fact that genetically improved cattle suffer more severely from poor housing, under-and malnutrition and subsequently become more susceptible to infection [34].

In the present study, level of awarness of cattle owners about BTB showed that $29.7 \%$ of the respondents knew that cattle can have tuberculosis, and $22.9 \%$ recognized that BTB is zoonotic. Ameni et al. [29] have indicated that lack of understanding regarding the zoonotic of BTB, food consumption behavior and poor sanitary measures is the potential risk of BTB to public health. Likewise, in this study, more than $80 \%$ of the respondents were consuming raw milk. Humans acquire the infection primarily by ingesting the agent in raw milk and milk products, and secondly by inhaling it when there is close physical contact between the owner and his/her cattle, especially at night since in some cases they share shelters with their animals[38]. Moreover, in Scotland it had been reported that the incidence of $M$. bovis infection in cattle herds has been increased since 2000 suggesting a similar rise in the incidence of $M$. bovis infection in humans [39].

\section{Conclusion}

The study showed that prevalence of BTB in cattle was low as compared to prevalence of BTB in intensive dairy farms in central Ethiopia. Even though the prevalence was low, high prevalence was found in herds that were managed under poor managerial inputs and in larger herd size as well as in exotic breeds than their crosses and Zebu breeds. The majority of cattle owners in the study area lack awareness about BTB and its public health significance; a large portion of the public had habit of drinking raw milk and eating raw meat implying the possible potential of acquiring BTB. Awareness rising of cattle owners about BTB and its transmission, and the zoonotic implication of BTB is of extreme importance for effective implementation of TB control measures.

\section{Acknowledgements}

The authors acknowledge Dilla University for its financial support to this research.The material support given by Akililu Lema Institute of Pathobiology for this work is also acknowledged. We are grateful to cattle owners, who were willing to involve in this study.

\section{References}

[1] Mbugi, E.V., Katale, B.Z., Kendall, S., Good, L., Kibiki, G.S., Keyyu, J.D., Godfrey-Faussett, P., Helden,P. and Matee, M.I. (2012). 'Tuberculosis cross-species transmission in Tanzania: Towards a One-Health concept', Onderstepoort. Journal of Veterinary Research,79:1-6.

[2] Buncic, S. (2006). Integrated Food Safety and Veterinary Public Health. $1^{\text {st }}$ ed. CABI, London, UK. Pp: 61.

[3] Amanfu, W. (2006). The situation of tuberculosis and tuberculosis control in animals of economic interest. Tuberculosis, 86:330-335.

[4] OIE(2010). Bovine tuberculosis. In: Manual of Diagnostic Tests and Vaccines for Terrestrial Animals. World Organization for Animal Health, Pp: 683-698.

[5] Tenguria, K.R., Khan, F.N., Quereshi,S. and Pandey, A. (2011). Review Article Epidemiological Study of Zoonotic Tuberculosis Complex (ZTBC).World Journalof Scienceand Technology, 1: 31-56. 
[6] Palmer, M.V., Thacker, T.C., Waters, W.R., Gort,C.A. and Corner, L.A. (2012). Mycobacterium bovis: A Model Pathogen at the Interface of Livestock, Wildlife, and Humans.Veterinary Medicine International, 1:17.

[7] Anonymous, (1994): Zoonotic tuberculosis (mycobacterium infection): amemorandum from WHO (with participation of FAO). Bulletin of World Health Organization, 72: 851-857.

[8] Ashford, D.A., Whitney, E., Raghunathan, P. and Cosivi, O. (2001). Epidemiology of selected mycobacteria that infect humans and other animals. Review of Science and Technology, Office International des Epizooties, 20: 105112.

[9] Cosivi, O., Grange, J.M., Dabron, C.J., Raviglione, M.C., Fujikura, T., Cousins, D., Robinson, R.A., Huchzermeyer, H.F., deKantor,I. and Meslin, F.X. (1998). Zoonotic tuberculosis due to Mycobacterium bovisin developing countries. Emerging Infectious Disease, 4:1-17.

[10] Kazwala, R.R., Kambarage, D.M., Daborn, C.J., Nyange, J., Jiwa, S.F. and Sharp, J.M. (2001). Risk factors associated with the occurrence of bovine tuberculosis in cattle in the Southern Highlands of Tanzania. Veterinary Research Communication, 25: 609-614.

[11] Ayele, W.Y., Neill, S.D., Zinsstag, J., Weiss,M.G. and Pavlik, I. (2004). Bovine tuberculosis: an old disease but a new threat to Africa. International Journal of Tubercleand Lung Disease, 8:924-937.

[12] de Kantor, I. N., LoBue, P. A., and Thoen, C. O.(2010). Human Tuberculosis Caused by Mycobacterium bovis in the United States, Latin America, and the Caribean. International Journal of Tubercle and Lung Disease, 14: $1369-1373$

[13] Michel, A., Müller, B. van Helden, P. (2010). Mycobacterium bovis at the animal-human interface: A problem,or not? Veterinary Microbiology, 140: 371-381.

[14] Thoen, C., LoBue,P. and de Kantor, I.(2010). Why has zoonotic tuberculosis not received much attention? International Journal of Tubercle and Lung Disease,14: 1073-1074.

[15] Ameni, G., Hewinson, G., Aseffa, A., Young,D. and Vordermeier, M. (2008). Appraisal of interpretation criteria for the comparative intradermal tuberculin test for diagnosis of tuberculosis in cattle in Central Ethiopia. ClinicalVaccine and Immunology, 15:1272-1276.

[16] Regassa, A., Medhin, G. and Ameni, G. (2008). Bovine tuberculosis is more prevalent in cattle owned by farmers with active tuberculosis in central Ethiopia. Veterinary Journal, 178:119-125.

[17] Fetene, T. and Kebede, N. (2009). Bovine tuberculosis of cattle in three districts of north western Ethiopia. Tropical Animal Health and Production, 41:273-277.

[18] Tschopp, R., Schelling, E. Hattendorf, J. Young, D. Aseffa, A. and Zinsstag, J. (2010). Repeated cross-sectional skin testing for bovinetuberculosis in cattle kept in a traditional husbandry systemin Ethiopia. Veterinary Record, 167: 250-256.

[19] Firdessa, R., Tschopp, R. Wubete, A. Sombo, M. Hailu,E. et al. (2012). High Prevalence of Bovine Tuberculosis in Dairy Cattle in Central Ethiopia: Implications for the Dairy
Industry and Public Health. PLoS ONE, 7: e52851.

[20] Ameni G. and Erkihun, A. (2007). Bovine tuberculosis on small-scale dairy farms in Adama Town, central Ethiopia, and farmer awareness of the disease. Review of Science and Technology, Office International des Epizooties, 26:711-9.

[21] Edginton, M.E., Sekatane, C.S. and Goldstein. S.J. (2002). Patients' beliefs: do they affect tuberculosis control? A study in a rural district of South Africa. International Journal of Tubercle and Lung Disease, 6:1075-1082.

[22] Grange, J.M., Daborn, C. and Cosivi, O. (1994). HIVrelated tuberculosis due to Mycobacterium bovis. EurRespir. J., 7: 1564-1566.

[23] Girmay G., Pal, M., Deneke, Y., Weldesilasse,G., and Equar, Y. (2012). Prevalence and public health importance of bovine tuberculosis in and around Mekelle town, Ethiopia.International Journalof Livestock Research, 2: 180-188.

[24] SNV (2008). Dairy Investment Opportunities in Ethiopia. Addis Ababa: The Netherlands Development Organization. pp.1-48.

[25] Zeru, F., Romha, G., Berhe, G., Mamo, G., Sisay,T., and obena Ameni,G. (2014). Prevalence of bovine tuberculosis and assessment of Cattle owners' awareness on its public health implication in and around Mekelle, Northern Ethiopia. Journal of Veterinary Medicine and Animal Health, 6: 160-167.

[26] Ethiopian Mapping Authority, (1988).Five Thousand Years of Sustainablity? A Case study on Gedeo Land Use, Southern Ethiopia.

[27] Bennett, S., Woods, T., Liyanage,W.M. and Smith, D.L. (1991). A simplified general method for cluster-sample surveys of health in developing countries. World Health Statistics Quarterly, 44: 98-106.

[28] Regassa, A., Tassew, A., Amenu, K., Megersa, B., Abunna, F., Mekibib, B., Macrotty,T. and Ameni, G. (2010). A crosssectional study on bovine tuberculosis in Hawassa town and its surroundings, Southern Ethiopia. Tropical Animal Health and Production, 42:915-920.

[29] Radostits, O.M., Gay, C.C., Hinchcliff,K.W. and Constable, P.D. (2006). Diseases associated with Mycobacterium species. In: Veterinary Medicine. A Textbook of the Diseases of Cattle, Horses, Sheep, Pigs and Goats. $10^{\text {th }}$ ed. Edinburgh, London, New York, Oxford, Philadelphia, St Louis Sydney, Toronto, Pp: 1008-1017.

[30] Nicholson, M.J. and Butterworth, M.H. (1986). A guide to condition scoring of Zebu cattle. ILCA Addis Ababa, Ethiopia, Pp: 1-29.

[31] Ameni, G., Amenu, K. and Tibbo, M. (2003). Bovine tuberculosis: Prevalence and risk factor assessment in cattle and cattle owners in Wuchale-Jida district, Central Ethiopia. The International Journalof Appllied Researchand Veterinary Medicine, 1: 1-13.

[32] Elias, K., Hussein, D. Asseged, B. Wondwossen,T. and Gebeyehu, M. (2008).Bovine tuberculosis in Addis Ababa dairy farms.Review of Science and Technology, Office International des Epizooties, 27: 915 -923. 
[33] Tsegaye, W., Aseffa, A. Mache, Mengistu, Y. Berg,S. and Ameni, G. (2010).Conventional and Molecular Epidemiology of Bovine Tuberculosis in Dairy Farms in Addis Ababa City, the Capital of Ethiopia. The International Journal of Appllied Research and Veterinary Medicine, 8: 143-151.

[34] O'Reilly, L.M. and Daborn, C.J. (1995). The epidemiology of Mycobacterium bovisinfections in animals and man: a review. Tuberculosisand Lung Disease, 76: 1-46.

[35] OIE (1996). Diagnosis of bovine tuberculosis. In: Manual of standards for diagnostic tests and vaccines, Pp: 267-71.

[36] Barwinek, F. and Taylor, N.M. (1996). Assessment of the socio-economic importance of bovine Tuberculosis in Turkey and possible strategies for control and eradication, Turkish-German Animal Health information project. General directorate of protection and control, Ankara.
Eschborn: Deutsche Gesells ChaftfuerTechnische Zusammenarbeit, Pp: 3-45.

[37] Nega, M., Mazengia,H. and Mekonen, G. (2012).Prevalence and zoonotic implications of bovine tuberculosis in Northwest Ethiopia.International Journalof Medicineand Medical Science, 2: 188-192.

[38] Andersen, P. (1997). A review: host responses and antigens involved in protective immunity to Mycobacterium tuberculosis. Scandinavian Journalof Immunology, 45: 115131.

[39] Stewart, W.C., Champion, J., McMenamin, J., Young, D., Browning, L.M., Johnston, F. and Reilly, W.J. (2005). Twenty years of Mycobacterium bovis infection in people and cattle in Scotland. NHS, National Service Scotland. A poster produced by the Graphics Section, Health Protection Scotland. 